\title{
Two geographically separated food-borne outbreaks in Sweden linked by an unusual Cryptosporidium parvum subtype, October 2010
}

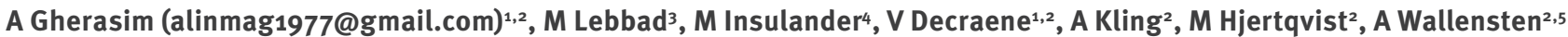

1. European Programme for Intervention Epidemiology Training (EPIET), European Centre for Disease Prevention and Control (ECDC), Stockholm, Sweden

2. Department of Analysis and Prevention, Swedish Institute for Communicable Disease Control (SMI), Solna, Sweden

3. Department of Diagnostics and Vaccinology, Swedish Institute for Communicable Disease Control, Solna, Sweden

4. Department of Communicable Disease Control and Prevention, Stockholm County, Sweden

5. Uppsala University, Uppsala, Sweden

Citation style for this article:

Gherasim A, Lebbad M, Insulander M, Decraene V, Kling A, Hjertqvist M, Wallensten A. Two geographically separated food-borne outbreaks in Sweden linked by an unusual Cryptosporidium parvum subtype, October 2010. Euro Surveill. 2012;17(46):pii=20318. Available online: http://www.eurosurveillance.org/ViewArticle. aspx?Articleld $=20318$

Article submitted on 16 May 2012 / published on 15 November 2012

The number of sporadic cases of Cryptosporidium identified in the Stockholm county area increased above the expected limit during October 2010. Additionally, two food-borne outbreaks of cryptosporidiosis occurred in two other Swedish cities: Umeå (4 October) and Örebro (9 October). The outbreak investigations did not reveal any responsible food item, however fresh herbs were suspected. Thirty stool samples, originating from all three events, tested positive for Cryptosporidium oocysts. Polymerase chain reaction (PCR) and subsequent restriction fragment length polymorphism (RFLP) revealed that 27 individuals were infected with C. parvum, two with C. hominis, and one with $C$. felis. Using sequence analysis of the GP6o glycoprotein gene, a polymorphic marker with high intra-species diversity, we identified the same $C$. parvum subtype IIdA24G1 in samples from both the Umea outbreak and the Stockholm area cases, thus indicating a possible outbreak in the Stockholm area and establishing a link between these two events. C. parvum IIdA24G1 has not previously been described in connection with a food-borne outbreak. For the outbreak in Örebro, another subtype was identified: C. parvum IIdA20G1e. These findings demonstrate that subtyping $C$. parvum isolates using GP6o gene amplification can be used to link cases in an outbreak investigation and we recommend its use in future similar events.

\section{Introduction}

Cryptosporidiosis is a diarrhoeal disease caused by protozoa of the genus Cryptosporidium. Human infection is predominantly caused by the species $C$. hominis and $C$. parvum [1]. While $C$. hominis infection affects only humans $[2,3], C$. parvum can infect a wider range of mammals. The transmission route is faecal-oral and may be caused by direct contact with infected persons or animals, or indirectly by either ingesting contaminated drinking water or water during aquatic recreational activities or consuming contaminated food. Watery diarrhoea with sudden onset is the most common symptom but abdominal pain, low-grade fever, nausea, dehydration, and weight loss also occur. The incubation period may vary between two and 12 days and symptoms can last up to two weeks [1]. Infections are usually self-limited in individuals without underlying conditions but for the immunocompromised diarrhoea can be prolonged, severe, and life-threatening [4].

Worldwide, cases of cryptosporidiosis may be detected sporadically or as part of water-borne or food-borne outbreaks. Food-borne outbreaks are less often detected and described than water-borne outbreaks. A recent review article found that, in the last decade, only 15 of 71 worldwide Cryptosporidium-linked outbreaks appeared to be correlated to food-borne transmission [2]. Consumption of fresh vegetables has been associated with cryptosporidiosis in Finland, Denmark and Sweden $[1,5,6]$. In the United States (US) insufficiently ozonated apple cider was described as a source of infection for a cryptosporidiosis outbreak [7], while one report documented contamination of food by a food handler [8].

In Sweden, cryptosporidiosis has been a notifiable disease since 2004. Overall, the incidence of cryptosporidiosis in Sweden has increased from $0.76 / 100,000$ in 2005 to $1.7 / 100,000$ in 2009 [9], with a seasonal peak during late summer months and autumn. However, the reported data are likely to underestimate the cryptosporidiosis burden since most laboratories do not test for Cryptosporidium unless specifically requested [6].

Several fingerprinting tools have been developed to examine the population structure and transmission dynamics of $C$. parvum and $C$. hominis, including sequencing of the 6o-kDa glycoprotein (GP6o) gene [10]. The GP6o gene is the most polymorphic gene 
identified in Cryptosporidium spp. to date, and has been used to further classify $C$. parvum and $C$. hominis into different allele families and subtypes [11]. Sequencing of the GP6o gene, including the microsatellite region, has provided a clearer understanding of the host specificity of $C$. parvum [12,13] and has also proved to be a useful tool in investigations of Cryptosporidium outbreaks [10,14]. In Sweden, in addition to being based on information from the GP15 sequence within the GP6o gene, subtyping also relies on analysis of the mini- and microsatellite loci MS1 and TP14. This allowed to identify two different sources of a C. parvum outbreak in relation to exposure to outdoor swimming-pool water [15].

In Stockholm county the incidence of cryptosporidiosis increased two fold in October 2010 (1.26/100.000), compared to October 2009 (0.64/100.000). The number of cases diagnosed in October 2010 was 26, more than three times higher than the average number of cases ( 8 cases; range: $1-26$ cases) reported for the same month in Stockholm in the past six years.

The preliminary investigation initially revealed that three of the cases had attended a national conference organised in Umeå (Västerbotten county, northern Sweden) between 4 and 5 October 2010 where a Cryptosporidium outbreak occurring in parallel was revealed. Additionally during October 2010, Cryptosporidium cases were reported among participants at a private party in the city of Örebro (Örebro county, central Sweden). We investigated the increased number of cryptosporidiosis cases in the Stockholm area, as well as the outbreaks in Umeå and Örebro in order to assess the magnitude and to identify the potential sources and vehicles of the disease. Furthermore, for the first time in Sweden, we explored the possibility of a connection between the three events using a molecular subtyping method based on nested polymerase chain reaction (PCR) GP6o gene amplification in real time.

\section{Methods}

\section{Epidemiological investigation}

Cryptosporidium cases confirmed in the Stockholm area were interviewed by phone using a standardised questionnaire regarding possible exposures in the two weeks prior to onset of symptoms. Specifically, we enquired about possible places of infection, history of travelling abroad, visits to swimming pools, meals at restaurants and food history.

We investigated the outbreaks in Umeå and Örebro using a cohort study approach for each event. We formulated the hypothesis that people became ill with gastrointestinal symptoms after consuming certain food items contaminated with Cryptosporidium oocysts. We defined a probable case as a person who attended the conference (Umeå) or party (Örebro) and developed diarrhoea (more than 3 loose stools/day) in the following 2-12 day interval. A confirmed case was any person who fulfilled the probable case definition and had a positive stool sample for Cryptosporidium oocysts.

Complete participant lists with email addresses were available for both events. We used a web-based questionnaire (Artologik - Artisan Global Software, Sweden; www.artologik.com) to collect data from conference attendees and staff in Umeå, as well from party guests in Örebro. We enquired about personal data (age, sex, place of residence), illness (symptoms, day of onset, duration and severity), meals attended and food items consumed. We estimated food-specific attack rates $(A R)$, relative risks (RR) and 95\% confidence intervals ( $95 \% \mathrm{Cl}$ ), for each meal served and each food item or beverage consumed. Bivariate analysis of the individual food items served during conference meals was restricted to persons who attended those meals. The risk ratios which were significant in the bivariate analysis ( $p<0.05$ ) were adjusted using binomial regression. We performed data analysis using Microsoft Excel and STATA 10 (StataCorp, USA).

An environmental investigation was carried out at the Umeå conference centre in order to evaluate food safety procedures.

\section{Laboratory investigation}

Faecal specimens included in this study originated either from sporadic cases from the Stockholm/Uppsala area $(67 \mathrm{~km}$ north of Stockholm) or from patients connected to the outbreaks in Umeå or Örebro. Stool samples were checked for the presence of Cryptosporidium at the regional laboratories. Identification of oocysts was performed using microscopy of acid-fast stained smears.

\section{Sample collection and DNA extraction}

Samples containing Cryptosporidium oocysts were submitted to the Swedish Institute for Communicable Disease Control (SMI) for further species and subtype identification. DNA was extracted directly from stool specimens using QIAampDNA mini kit (Qiagen, Hilden, Germany) according to the manufacturer's recommendations. Disruption of the oocysts using a MiniBeadBeater (Biospec Products Inc., Beatsville) was performed before the extraction procedure.

Species determination and subtyping

Species identification was determined by PCR and subsequent restriction fragment length polymorphism (RFLP) as described previously [16]. This technique amplifies 830-840 bp of the small sub-unit rRNA (SSU rRNA) gene by nested PCR and differentiates Cryptosporidium species by banding patterns using restriction analysis of the secondary PCR product with the enzymes Sspl and Vspl.

For subtype analysis, a nested PCR which amplifies the GP60 gene was used as described elsewhere $[17,18]$. 
Bidirectional sequencing was performed on all amplicons obtained. Subtypes within GP6o allele families were determined [17]. The sequences were compared with published sequences in the GenBank database using the basic local alignment search tool (BLAST) tool (http://www.ncbi.nlm.nih.gov/BLAST). Representative sequences were deposited in GenBank under the following accession numbers: JQ028865-JQ028868.

\section{Results}

\section{Epidemiological investigation}

Stockholm cases investigation

In total, 34 laboratory-confirmed Cryptosporidium cases were identified in Stockholm county between 11 October and 30 November 2010, of which 31 were interviewed. Two cases stated that they had travelled to the Canary Islands and Cuba, respectively, 14 days prior to onset of symptoms. For 24 cases, the most probable place of infection was considered to be the Stockholm/ Uppsala area. Of these, 11 were female. The median age of the cases was 30 years (range: 6-54). None of the cases were hospitalised. Twenty individuals reported having lunch daily, two weeks prior to onset of symptoms, in restaurants close to their work offices in Stockholm or Uppsala. The interviews revealed no common food item consumed by the cases.
One case reported that she and nine work colleagues from Stockholm attended a conference in Umeå between 4 and 5 October. Five individuals, in this group fell ill with gastrointestinal symptoms after that event. This case proved to be the first laboratory-confirmed case of Cryptosporidium associated with the conference in Umeå. The four colleagues that showed similar symptoms were also confirmed with cryptosporidiosis.

\section{Umeå outbreak}

The national conference organised in Umeå, and attended by some of the cases diagnosed in Stockholm, had taken place between 4 and 5 October with 278 participants (240 attendees and 38 staff). Of 278 participants 203 replied to the questionnaire, of which eight were conference centre employees. Of the respondents, $118 / 203$ (58\%) were female and the respondents' median age was 46 years (range: $18-76$ ). Aside from the cases who attended the conference and were identified in Stockholm, the web-based questionnaire allowed us to additionally detect 89 probable cases of whom nine were confirmed ( $44 \%$ attack rate among respondents). Most of the cases 58/89 (65\%) were female and the cases median age was 46 years (range: 24-70). The main symptoms were diarrhoea for all cases $(100 \%)$, bloating for $81 / 89(91 \%)$ and abdominal pain for $69 / 89(78 \%)$. None of the cases were hospitalised. The median incubation period was seven

\section{FIGURE}

Number of probable cases by date of symptom onset, Cryptosporidium parvum outbreak, Umeå, October 2010 (n=89)

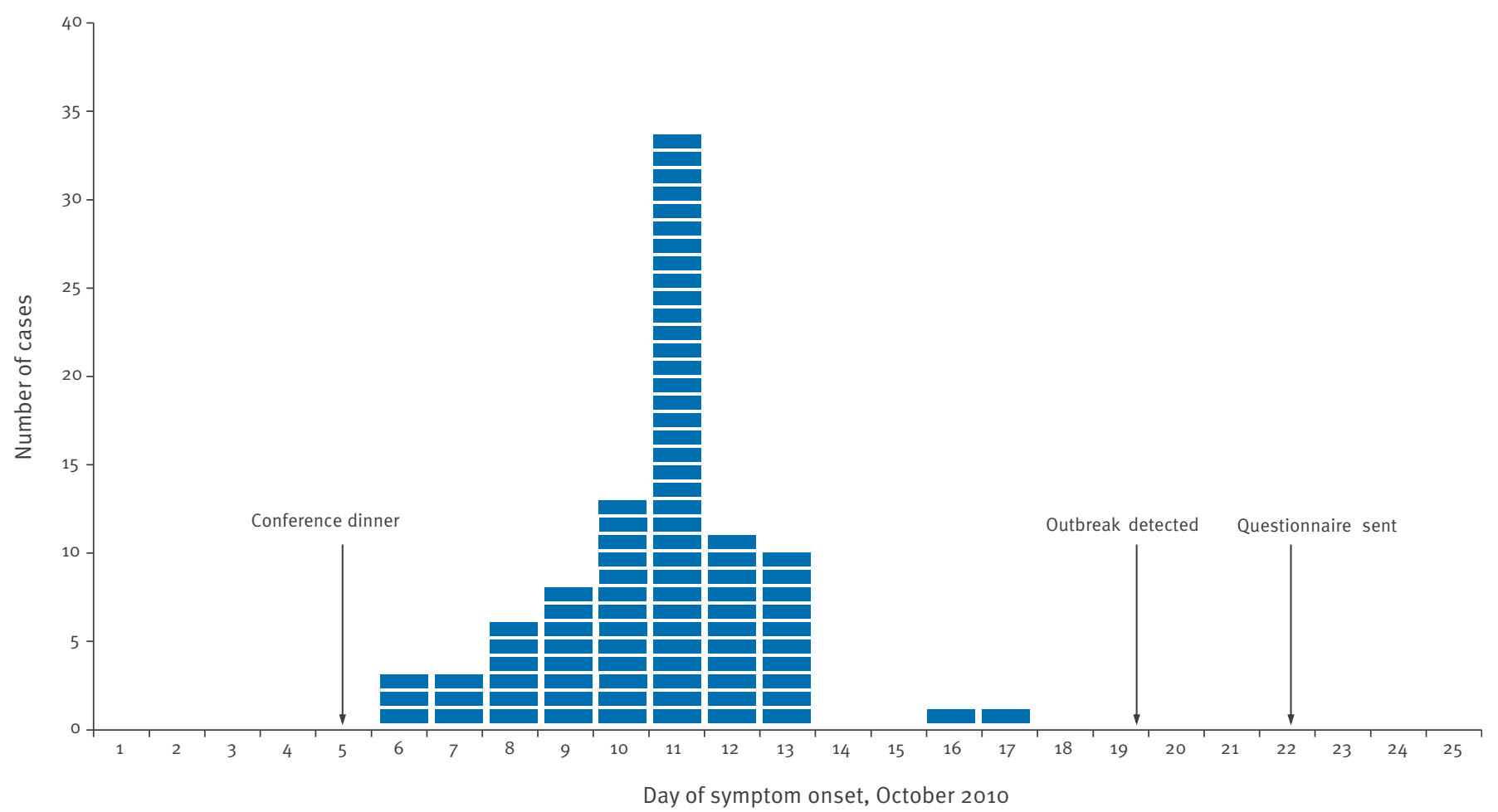


days (range: 2-13) (Figure), while the median duration of symptoms was four days (range: 2-21). Additionally, five more confirmed Cryptosporidium cases attending the conference, were diagnosed elsewhere in Sweden and reported to the Swedish national surveillance system (SmiNet) as linked to the Umeå outbreak.

The attendees were served four meals during the conference. On 4 October there was an afternoon coffee-break and a two course dinner (main course and dessert), preceded by a drinks reception. On 5 October, only a morning coffee-break was organised. The only meal significantly associated with the cases was the main course of the dinner served on 4 October (RR: 24; $95 \% \mathrm{Cl}: 3.4-167 ; \mathrm{p}=0.000)$. In the bivariate analysis of food items served during this main course, the chanterelle sauce had the highest risk ratio (RR: $4.2 ; 95 \% \mathrm{Cl}$ : $0.7-27 ; p=0.042$ ). Also, people who ate at least one of the five herbs served as salad garnish had two times higher risk of becoming ill than people who did not (Table 1).

Besides food items included in the main course, we identified other theoretically possible sources of infection as: components of the dessert (mascarpone, cooked apples and hazelnuts), mixed nuts and water from a water dispenser (Table 1). In a binomial regression model we estimated an adjusted RR (aRR) of 11.3 ( $95 \% \mathrm{Cl}: 1.5-83.1$ ) for the main course. Mixed nuts and drinking from the water dispenser were also significant with aRRs of 1.5 (95\% Cl: $1.2-2)$ and $1.6(95 \% \mathrm{Cl}$ : 1.1-2.3) respectively. The dessert components had no association with disease: aRR $1.3(95 \% \mathrm{Cl}$ : 0.7-2.3).

The environmental investigation performed at the Umeå conference centre revealed that none of the restaurant staff had gastrointestinal symptoms prior to the conference. Among the eight employees who replied, one was classified as a probable case - a woman who served at the dinner, ate the same meal as the guests, and became ill afterwards. None of the employees submitted a stool sample for Cryptosporidium oocyst identification. No violations of food safety procedures were discovered during the investigation. No food-leftovers were available for microbiological analysis.

\section{TABLE 1}

Relative risks for food items served at one conference dinner, 95\% confidence intervals and p-values, Cryptosporidium outbreak, Umeå, Sweden, 4 October 2010

\begin{tabular}{|c|c|c|c|c|c|c|c|c|c|c|}
\hline \multirow[b]{2}{*}{ Exposure } & \multicolumn{3}{|c|}{ Exposed } & \multicolumn{3}{|c|}{ Unexposed } & \multirow{2}{*}{$\begin{array}{l}\text { Risk } \\
\text { ratio }\end{array}$} & \multirow{2}{*}{$\begin{array}{l}95 \% \\
\text { confidence } \\
\text { interval }\end{array}$} & \multirow[b]{2}{*}{$\mathrm{p}$-value ${ }^{\mathrm{a}}$} & \multirow{2}{*}{$\begin{array}{l}\text { Percentage (\%) of cases } \\
\text { exposed in relation to } \\
\text { the total number of cases } \\
\qquad(\mathrm{N}=89)\end{array}$} \\
\hline & Total & Cases & $\begin{array}{c}\text { Attack } \\
\text { rate (\%) }\end{array}$ & Total & Cases & $\begin{array}{c}\text { Attack } \\
\text { rate (\%) }\end{array}$ & & & & \\
\hline $\begin{array}{c}\text { Chanterelle } \\
\text { sauce }\end{array}$ & 138 & 83 & 60.1 & 7 & 1 & $14 \cdot 3$ & 4.2 & $0.7-27$ & 0.042 & 93 \\
\hline Garnish $^{\mathrm{b}}$ & 101 & 62 & 61.4 & 13 & 4 & 30.8 & 2 & $0.8-4.6$ & 0.042 & 69 \\
\hline $\begin{array}{l}\text { Rocket } \\
\text { salad }\end{array}$ & 79 & 50 & 63.3 & 10 & 2 & 20 & 3.2 & $0.9-11.1$ & 0.015 & 56 \\
\hline Parsley & 69 & 43 & 62.3 & 10 & 2 & 20 & 3.1 & $0.9-10.1$ & 0.016 & 48 \\
\hline Leek shoots & 67 & 41 & 61.2 & 10 & 2 & 20 & 3.1 & $0.9-10.7$ & 0.019 & 46 \\
\hline Green Salad & 70 & 43 & 61.4 & 9 & 2 & 22.2 & 2.8 & $0.8-9.5$ & 0.034 & 48 \\
\hline Pea shoots & 72 & 42 & 58.3 & 10 & 3 & 30 & 1.9 & $0.7-5.1$ & 0.173 & 47 \\
\hline Fillet of pork & 147 & 85 & 57.8 & 9 & 3 & 33.3 & 1.7 & $0.7-4.4$ & 0.179 & 96 \\
\hline $\begin{array}{l}\text { Potatoes/ } \\
\text { root } \\
\text { vegetables }\end{array}$ & 144 & 81 & 56.2 & 7 & 4 & 57.1 & 1.0 & $0.5^{-1.9}$ & 1 & 91 \\
\hline Hazelnuts ${ }^{c}$ & 93 & 58 & 62.4 & 24 & 7 & 29.2 & 2.1 & $1.1-4$ & 0.005 & 65 \\
\hline $\begin{array}{c}\text { Water } \\
\text { (from water } \\
\text { dispenser) }^{\mathrm{d}}\end{array}$ & 79 & 44 & $55 \cdot 7$ & 84 & 24 & 28.6 & 1.9 & $1.3-2.8$ & 0 & 49 \\
\hline Mixed nuts ${ }^{d}$ & 54 & 39 & 72.2 & 45 & 21 & 46.7 & 1.5 & $1-2.2$ & 0.013 & 44 \\
\hline
\end{tabular}

a The p-values were derived through Fisher's exact test.

b The variable 'garnish' was created in the analysis based on consumption of at least one of the five herbs served at dinner (rocket salad, parsley, leek shoots, green salad, pea shoots).

Component of the dinner's dessert.

$\mathrm{d}$ xBoth water from the water dispenser and mixed nuts were available for the entire duration of the conference on 4 and 50 0ctober 2010. 
Relative risks for foods and beverages served at a party, 95\% confidence intervals and p-values, Cryptosporidium outbreak, Örebro, Sweden, 9 October 2010

\begin{tabular}{|c|c|c|c|c|c|c|c|c|c|c|}
\hline \multirow[b]{2}{*}{ Exposure } & \multicolumn{3}{|c|}{ Exposed } & \multicolumn{3}{|c|}{ Unexposed } & \multirow{2}{*}{$\begin{array}{l}\text { Risk } \\
\text { ratio }\end{array}$} & \multirow{2}{*}{$\begin{array}{c}95 \% \\
\text { confidence } \\
\text { interval }\end{array}$} & \multirow[b]{2}{*}{$p$-value ${ }^{a}$} & \multirow{2}{*}{$\begin{array}{l}\text { Percentage (\%) of cases } \\
\text { exposed in relation to } \\
\text { the total number of cases } \\
(N=16)\end{array}$} \\
\hline & Total & Cases & $\begin{array}{c}\text { Attack } \\
\text { rate (\%) }\end{array}$ & Total & Cases & $\begin{array}{c}\text { Attack } \\
\text { rate (\%) }\end{array}$ & & & & \\
\hline Salad & 18 & 15 & 83.3 & 3 & 0 & 0 & NA & NA & 0.015 & 94 \\
\hline Tart & 21 & 16 & 76.2 & 2 & 0 & 0 & NA & NA & 0.083 & 100 \\
\hline Wine sauce & 16 & 10 & 62.5 & 4 & 3 & 75 & 0.8 & $0.4-1.6$ & 1 & 63 \\
\hline $\begin{array}{c}\text { Whiskey } \\
\text { sauce }\end{array}$ & 17 & 12 & 70.6 & 2 & 2 & 100 & 0.7 & $0.5-0.9$ & 1 & 75 \\
\hline Beef steak & 24 & 16 & 66.7 & 0 & 0 & 0 & NA & NA & NA & 100 \\
\hline Mixed fruits & 22 & 16 & 72.7 & 0 & 0 & 0 & NA & NA & NA & 100 \\
\hline Beer & 10 & 4 & 40 & 10 & 9 & 90 & 0.4 & $0.2-0.9$ & 0.057 & 25 \\
\hline Cider & 3 & 3 & 100 & 14 & 7 & 50 & 2 & $1.2-3.4$ & 0.228 & 19 \\
\hline Milk & 6 & 5 & 83.3 & 12 & 6 & 50 & 1.7 & $0.8-3.2$ & 0.316 & 31 \\
\hline Tea & 2 & 2 & 100 & 15 & 8 & 53.3 & 1.9 & $1.1-3$ & 0.485 & 13 \\
\hline $\begin{array}{c}\text { Sparkling } \\
\text { water }\end{array}$ & 9 & 6 & 66.7 & 10 & 5 & 50 & 1.3 & $0.6-2.9$ & 0.65 & 38 \\
\hline Wine & 17 & 11 & 64.7 & 5 & 3 & 60 & 1.1 & $0.5-2.4$ & 1 & 69 \\
\hline
\end{tabular}

NA: not applicable.

a The p-value was derived through Fisher's exact test.

\section{Örebro outbreak}

Of 34 participants at the party in Örebro on 9 October, 24 replied to the questionnaire of which 14 (58\%) were female. Sixteen individuals, including 12 (75\%) female met the probable case definition, giving an attack rate of $67 \%$ among respondents. Only two laboratory-confirmed cases were indentified, whose samples were also submitted for genotyping. Being a female was a risk factor for becoming a case (RR: $2.4 ; p=0.02$ ), and party guests aged under 30 were at higher risk of being a case than older people (RR: $2.5 ; p=0.007$ ). Due to small population size (no cases unexposed), the RR and $95 \% \mathrm{Cl}$ could not be estimated for all the food and beverages served at the party (Table 2 ).

\section{Laboratory investigation}

In total, 31 samples positive for Cryptosporidium oocysts were sent to SMI for molecular investigation; 23 originated from cases from the Stockholm/Uppsala area (including the two cases with a history of travel abroad), six from the Umeå outbreak and two from the Örebro outbreak.

\section{Species and subtype identification}

Species determination and subtyping was successfully accomplished for 30 of 31 Cryptosporidium samples (Table 3). RFLP analysis of the amplified products of the SSU rRNA gene revealed C. parvum in 27 isolates, $C$. hominis in two and $C$. felis in one.
Subtyping based on sequencing of the GP60 gene amplicons identified five different $C$. parvum subtypes belonging to either allele family Ila or IId. The most frequent subtype identified, IIdA24G1, was found in 21 of the 27 C. parvum isolates, of which 15 originated from the Stockholm/Uppsala area and six from the outbreak linked to the Umeå conference. $C$. parvum subtype IIdA20G1e was identified in two isolates related to the Örebro outbreak. For the remaining six patients infected with $C$. parvum, four different subtypes were identified: IldA2oG1e $(n=2)$, IlaA2oR1 $(n=1)$, IlaA15G2R1 $(n=1)$ and IlaA16G1R1 $(n=2)$. C hominis subtypes IbA10G and $\mathrm{IdA}_{15}$ were isolated from two patients who had travelled abroad.

\section{Discussion}

We investigated an increase in Cryptosporidium cases in the Stockholm/Uppsala area which subsequently led to the discovery of a C. parvum food-borne outbreak comprising 89 probable cases in the geographically distant city of Umeå in Northern Sweden. The laboratory results revealed the same $C$. parvum subtype (IIdA24 $\mathrm{G}_{1}$ ) harboured by most of the cases from Stockholm/Uppsala area (15 of 20), thus confirming the outbreak in this region. The same subtype, $C$. parvum IIdA24G1 was also identified in all six isolates available from the Umeå cases. 
Provenance of clinical isolates with Cryptosporidium species characterised, Cryptosporidium outbreaks, Sweden, October-November $2010(n=30)$

\begin{tabular}{|c|c|c|c|c|c|}
\hline \multirow{2}{*}{ Species and subtype ${ }^{a}$} & \multicolumn{4}{|c|}{ Probable locations of infection } & \multirow{2}{*}{ Total } \\
\hline & Stockholm /Uppsala & Umeå & Örebro & Others & \\
\hline \multicolumn{6}{|c|}{ Cryptosporidium hominis } \\
\hline $\mathrm{IbA} 10 \mathrm{G} 2$ & NA & NA & NA & Canary Islands & 1 \\
\hline $\mathrm{IdA} 15$ & NA & NA & NA & Cuba & 1 \\
\hline \multicolumn{6}{|l|}{ Cryptosporidium parvum } \\
\hline IIdA2oG1e & NA & NA & 2 & NA & 2 \\
\hline $\mathrm{IIdA} 24 \mathrm{G}_{1}$ & 15 & 6 & NA & NA & 21 \\
\hline IlaA2oR1 & 1 & NA & NA & NA & 1 \\
\hline IlaA15G2R1 & 1 & NA & NA & NA & 1 \\
\hline IlaA16G1R1 & 2 & NA & NA & $\mathrm{NA}$ & 2 \\
\hline \multicolumn{6}{|l|}{ Cryptosporidium felis } \\
\hline ND & 1 & & NA & NA & 1 \\
\hline Total & 20 & 6 & 2 & 2 & 30 \\
\hline
\end{tabular}

NA: not applicable; ND: not determined.

a Unless otherwise specified.

Among the Umeå conference attendees, the distribution of cases over time suggested a food-borne point source outbreak with the most probable exposure being the dinner's main course. Bivariate analysis of food items indicated the chanterelle sauce and vegetables used as garnish as possible vehicles of transmission. These results could be explained by the fact that both food items were served on the same plate. Chanterelle sauce was prepared using high temperature cooking, while the salad garnish was the only food item served uncooked, thus increasing the possibility of harbouring the parasite. It has been previously documented that Cryptosporidium oocysts may enter and survive within the leaves of vegetables, thus increasing the likelihood of transmission if the vegetables are served without prior high temperature cooking [19]. Furthermore, simple washing may fail to remove all Cryptosporidium oocysts from contaminated vegetables [20]. In 2008, a C. parvum outbreak in Sweden was linked to chanterelle sauce with fresh parsley added after the preparation of the sauce [6], while in Finland a salad mixture was the suspected vehicle for a C. parvum outbreak [5]. Moreover, two other foodborne outbreaks were described recently in Sweden, in connection with parasite-contaminated vegetables. Sugar snap peas imported from Guatemala, harbouring Cyclospora cayetanensis, were the suspected vehicle for a cyclosporiasis outbreak in Stockholm 2009 [21]. The same year, the first reported food-borne outbreak associated with microsporidia (Enterocytozoon bieneusi) was described in connection with pre-washed, ready-to-eat cucumber [22]. These findings support the hypothesis that salad garnish could have been the vehicle for the Umeå outbreak.

We could not find an explanation for the association between disease and either the water dispenser or the mixed nuts. Bivariate analysis showed that 58 of 89 cases stated that they ate mixed nuts, while water from water dispenser could potentially explain only 44 cases. Since no water samples were available, the presence of oocysts in the water from the dispenser or tap could not be verified. There was no increase in numbers of gastrointestinal illness reported in Umeå during October, leading to the conclusion that the outbreak did not originate from the city's water-supply system.

We could not rule out the possibility that one of the conference centre staff could have been the source of the outbreak, as not all of the employees responded to the questionnaire and none provided a stool sample.

Eleven of 15 cases from the Stockholm/Uppsala area outbreak, infected with the same genotype (C. parvum IIdA24G1) reported having lunch frequently in restaurants and bars close to their offices in Stockholm and Uppsala, two weeks prior to symptom onset. The investigation revealed no common place of exposure for these cases, nor possible common food item eaten. Furthermore, we could not identify a common food item consumed by Umeå and Stockholm/Uppsala cases.

The outbreak in Örebro affected a smaller number of people compared to Umeå. Nevertheless, the attack 
rate was high and the distribution of cases over time also indicated a point source food-borne outbreak. Only two stool samples were available from the participants, and the same Cryptosporidium subtype, IldA20G1e, was identified in both. Due to small sample size, no significant association could be determined between the exposure to any food item and the disease.

Our epidemiological investigations had several limitations. Due to the long incubation period, the epidemiological data were obtained almost three weeks after the conference so recall bias may have led to misclassification of exposures. Since the food items of the main course were all served on the same plate, cross-contamination between food items was possible. We did not enquire about the amount of food items consumed and were therefore unable to calculate dose response relationships. For the interviewed cases in Stockholm, it is possible that some cases could not remember exactly if they ate the salad garnish. Poor recall of garnish items is common and was recently documented in Germany during a large outbreak of Escherichia coli $\mathrm{O}_{104}: \mathrm{H}_{4}$ associated with sprouts [23]. Moreover, because no food leftovers were available for microbiological analysis, we could not determine the presence of Cryptosporidium oocysts in any of the suspected vegetables. The origin of the vegetables could not be traced further than the wholesalers in Sweden and consequently, the mechanism of food contamination could not be determined. In the future, increasing the speed and ease of tracing suspected vegetables would be useful, especially since herbs appear to play an important role in outbreaks of gastrointestinal infections worldwide.

C. parvum subtype IIdA24G1 was identified in all samples available from Umeå and considered the probable aetiologic agent for this outbreak. All cases with this subtype from Umeå and Stockholm/Uppsala region had sequences that were $100 \%$ identical, suggesting a possible common vehicle for the two outbreaks. The presence of this subtype in humans is scarcely documented and has not previously been identified in Swedish patients [24]. Only one C. parvum IIdA24G1 sequence available in GenBank (accession number: HQ005751) and isolated from a sporadic C. parvum case in the United Kingdom was $100 \%$ identical with the one described in our report [13]. The subtype IIdA24G1 has also been described in human cases from Jordan and Australia $[25,26]$ as well as in lambs and goat kids in Spain [27]. To our knowledge this is the first time that the $C$. parvum IIdA24G1 genotype has been linked to a food-borne outbreak.

Subtype C. parvum IIdA20G1e was isolated from the Örebro cases, suggesting that this event was not linked to the outbreaks in Stockholm and Umeå. Five different variants have been described for this subtype, IIdA20G1a-e $[17,28]$. Interestingly, the same variant as in our outbreak isolates, IIdA20G1e, was described in a
Swedish calf, suggesting a possible zoonotic source for the Örebro outbreak [29].

The $C$. parvum IlaA2oR1 subtype, isolated from a case in the Stockholm area, has not been reported previously. The other two $C$. parvum subtypes (IlaA15G2R1 and IlaA $16 G_{1} R_{1}$ ) are commonly found worldwide, and recognised for their zoonotic potential $[2,13,25,27,30,31]$.

The sequence of the $C$. hominis $\mathrm{IbA}_{10 \mathrm{G} 2}$ isolated from the traveller to the Canary Islands was identical with the $C$. hominis subsequently isolated in Sweden from cryptosporidiosis cases during water-borne outbreaks in Östersund (November 2010) and Skellefteå (April 2011)[32]. This subtype was the most common in a study of Swedish patients with cryptosporidiosis [24] and it has also been identified as the most common $C$. hominis subtype worldwide [2,33]. The other C. hominis case with subtype IdA15 had visited Cuba, where this subtype was previously described in sporadic cases in children [34]. One patient was infected with C. felis, a Cryptosporidium species usually found in cats and rarely infecting humans [35].

The characterisation of Cryptosporidium isolates by the GP6o gene amplification method proved to be a useful tool in our investigation. The extra information supplied added important elements for the investigation of the three outbreaks in addition to providing valuable knowledge about cryptosporidiosis epidemiology in Sweden. Molecular characterisation of the isolates showed heterogeneity of subtypes among studied cases. There was a large variation in the GP6o gene with five different subtypes identified in 27 isolates. Subtypes isolated worldwide from sporadic or waterborne outbreaks, were also identified in Sweden by our study, as well as new or rare subtypes such as $C$. parvum IIdA24G1. Further studies are needed in order to improve the knowledge about cryptosporidiosis in Sweden.

It is important to bear in mind that we were only able to identify these cases as a result of our investigation into the cryptosporidiosis cases in Stockholm. We would therefore like to emphasise the importance both of testing for cryptosporidiosis in cases of diarrhoea (particularly domestic cases) and also of sending positive samples to the reference laboratory for genotyping. Molecular characterisation of isolates from cryptosporidiosis cases is not routinely performed in Sweden but we suggest that this method should be used in real time when investigating cryptosporidiosis cases that seem to cluster or belonging to an outbreak. 


\section{Acknowledgments}

We would like to thank Västerbotten and Örebro County Medical Offices and the National Food Administration for the support provided during the Umeå and Örebro outbreak investigations. We also would like to acknowledge the contribution of EPIET coordinators in reviewing this manuscript. The EPIET fellowship of Alin Gherasim and Valérie Decraene is funded by the European Centre for Disease Prevention and Control (ECDC).

\section{References}

1. Ethelberg S, Lisby M, Vestergaard LS, Enemark HL, Olsen KE, Stensvold CR, et al. A foodborne outbreak of Cryptosporidium hominis infection. Epidemiol Infect. 2009;137(3):348-56.

2. Putignani L, Menichella D. Global distribution, public health and clinical impact of the protozoan pathogen cryptosporidium. Interdiscip Perspect Infect Dis. 2010;2010.

3. Chappell CL, Okhuysen PC, Langer-Curry R, Widmer G, Akiyoshi DE, Tanriverdi S, et al. Cryptosporidium hominis: experimental challenge of healthy adults. Am J Trop Med Hyg. 2006;75(5):851-7.

4. Aragon TJ, Novotny S, Enanoria W, Vugia DJ, Khalakdina A, Katz $\mathrm{MH}$. Endemic cryptosporidiosis and exposure to municipal tap water in persons with acquired immunodeficiency syndrome (AIDS): a case-control study. BMC Public Health. 2003;3:2.

5. Ponka A, Kotilainen H, Rimhanen-Finne R, Hokkanen $P$, Hanninen ML, Kaarna A, et al. A foodborne outbreak due to Cryptosporidium parvum in Helsinki, November 2008. Euro Surveill. 2009;14(28):pii=19269. Available from: http://www. eurosurveillance.org/ViewArticle.aspx?Articleld=19269

6. Insulander M, de Jong B, Svenungsson B. A food-borne outbreak of cryptosporidiosis among guests and staff at a hotel restaurant in Stockholm county, Sweden, September 2008. Euro Surveill. 2008;13(51):pii=19071. Available from: http://www.eurosurveillance.org/ViewArticle. aspx?Articleld $=19071$

7. Blackburn BG, Mazurek JM, Hlavsa M, Park J, Tillapaw M, Parrish $M$, et al. Cryptosporidiosis associated with ozonated apple cider. Emerg Infect Dis. 2006;12(4):684-6.

8. Quiroz ES, Bern C, MacArthur JR, Xiao L, Fletcher M, Arrowood MJ, et al. An outbreak of cryptosporidiosis linked to a foodhandler. J Infect Dis. 2000;181(2):695-700.

9. Smittskyddinstitutet (SMI). Statistik för cryptosporidiuminfektion. [Statistics for Cryptosporidium infection]. Solna:SMI. Swedish. [Accessed 15 Nov 2012]. Available from: http://www.smi.se/statistik/ cryptosporidiuminfektion/

10. Ng JS, Pingault N, Gibbs R, Koehler A, Ryan U. Molecular characterisation of Cryptosporidium outbreaks in Western and South Australia. Exp Parasitol. 2010;125(4):325-8.

11. Waldron LS, Power ML. Fluorescence analysis detects gp 60 subtype diversity in Cryptosporidium infections. Infect Genet Evol. 2011;11(6):1388-95.

12. Alves M, Xiao L, Sulaiman I, Lal AA, Matos O, Antunes F. Subgenotype analysis of Cryptosporidium isolates from humans, cattle, and zoo ruminants in Portugal. J Clin Microbiol. 2003;41(6):2744-7.

13. Chalmers RM, Smith RP, Hadfield SJ, Elwin K, Giles M. Zoonotic linkage and variation in Cryptosporidium parvum from patients in the United Kingdom. Parasitol Res. 2011;108(5):1321-5.

14. Grinberg A, Pomroy WE, Squires RA, Scuffham A, Pita A, Kwan E. Retrospective cohort study of an outbreak of cryptosporidiosis caused by a rare Cryptosporidium parvum subgenotype. Epidemiol Infect. 2011;139(10):1542-50.

15. Insulander M, Lebbad M, Stenstrom TA, Svenungsson B. An outbreak of cryptosporidiosis associated with exposure to swimming pool water. Scand J Infect Dis. 2005;37(5):354-60.

16. Xiao L, Singh A, Limor J, Graczyk TK, Gradus S, Lal A. Molecular characterization of cryptosporidium oocysts in samples of raw surface water and wastewater. Appl Environ Microbiol. 2001;67(3):1097-101.

17. Sulaiman IM, Hira PR, Zhou L, Al-Ali FM, Al-Shelahi FA, Shweiki $\mathrm{HM}$, et al. Unique endemicity of cryptosporidiosis in children in Kuwait. J Clin Microbiol. 2005;43(6):2805-9.

18. Glaberman S, Moore JE, Lowery CJ, Chalmers RM, Sulaiman I, Elwin K, et al. Three drinking-water-associated cryptosporidiosis outbreaks, Northern Ireland. Emerg Infect Dis. 2002;8(6):631-3.

19. Macarisin D, Bauchan G, Fayer R. Spinacia oleracea L. leaf stomata harboring Cryptosporidium parvum oocysts: a potential threat to food safety. Appl Environ Microbiol. 2010;76(2):555-9.

20. Ortega YR, Roxas CR, Gilman RH, Miller NJ, Cabrera L, Taquiri $C$, et al. Isolation of Cryptosporidium parvum and Cyclospora cayetanensis from vegetables collected in markets of an endemic region in Peru. Am J Trop Med Hyg. 1997;57(6):683-6.

21. Insulander M, Svenungsson B, Lebbad M, Karlsson L, de Jong B. A foodborne outbreak of Cyclospora infection in Stockholm, Sweden. Foodborne Pathog Dis. 2010;7(12):1585-7.

22. Decraene V, Lebbad M, Botero-Kleiven S, Gustavsson AM, Lofdahl M. First reported foodborne outbreak associated with microsporidia, Sweden, October 2009. Epidemiol Infect. 2012;140(3):519-27.

23. Buchholz U, Bernard H, Werber D, Bohmer MM, Remschmidt C, Wilking $\mathrm{H}$, et al. German outbreak of Escherichia coli $0_{104}: \mathrm{H}_{4}$ associated with sprouts. N Engl J Med. 2011;365(19):1763-70.

24. Insulander M, Silverlas C, Lebbad M, Karlsson L, Mattsson JG, Svenungsson B. Molecular epidemiology and clinical manifestations of human cryptosporidiosis in Sweden. Epidemiol Infect. 2012:1-12.

25. Waldron LS, Ferrari BC, Power ML. Glycoprotein 60 diversity in C. hominis and C. parvum causing human cryptosporidiosis in NSW, Australia. Exp Parasitol. 2009;122(2):124-7.

26. Hijjawi N, Ng J, Yang R, Atoum MF, Ryan U. Identification of rare and novel Cryptosporidium GP6o subtypes in human isolates from Jordan. Exp Parasitol. 2010;125(2):161-4

27. Quilez J, Torres E, Chalmers RM, Hadfield SJ, Del Cacho E, Sanchez-Acedo C. Cryptosporidium genotypes and subtypes in lambs and goat kids in Spain. Appl Environ Microbiol. 2008;74(19):6026-31.

28. Amer S, Honma H, Ikarashi M, Tada C, Fukuda Y, Suyama Y, et al. Cryptosporidium genotypes and subtypes in dairy calves in Egypt. Vet Parasitol. 2010;169(3-4):382-6.

29. Silverlas C, Naslund K, Bjorkman C, Mattsson JG. Molecular characterisation of Cryptosporidium isolates from Swedish dairy cattle in relation to age, diarrhoea and region. Vet Parasitol. 2010;169(3-4):289-95.

30. Alves M, Xiao L, Antunes F, Matos O. Distribution of Cryptosporidium subtypes in humans and domestic and wild ruminants in Portugal. Parasitol Res. 2006;99(3):287-92.

31. Xiao L, Zhou L, Santin M, Yang W, Fayer R. Distribution of Cryptosporidium parvum subtypes in calves in eastern United States. Parasitol Res. 2007;100(4):701-6.

32. Smittskyddinstitutet (SMI). Cryptosporidium i Östersund [Waterborne outbreak of cryptosporidiosis in Östersund, Sweden 2010]. Solna:SMI; Nov 2011. Swedish. Available from: http://www.smittskyddsinstitutet.se/upload/Publikationer/ Cryptosporidium-i-Ostersund-2011-15-4.pdf

33. Ng J, MacKenzie B, Ryan U. Longitudinal multi-locus molecular characterisation of sporadic Australian human clinical cases of cryptosporidiosis from 2005 to 2008. Exp Parasitol. 2010;125(4):348-56.

34. Pelayo L, Nunez FA, Rojas L, Wilke H, Furuseth Hansen E, Mulder B, et al. Molecular and epidemiological investigations of cryptosporidiosis in Cuban children. Ann Trop Med Parasitol. 2008;102(8):659-69.

35. Elwin K, Hadfield SJ, Robinson G, Chalmers RM. The epidemiology of sporadic human infections with unusual cryptosporidia detected during routine typing in England and Wales, 2000-2008. Epidemiol Infect. 2012;140(4):673-83. 